\title{
EMBALAJE SIN FONDO
}

\author{
Aníbal Sierralta Ríos*
}

$\mathbf{L}$

a empresa Harman \& Cía S.A., de porte medio, opera en el ramo de la exportación de productos frescos y agroindustriales. Desde 1987 empez6 a considerar seriamente la posibilidad de exportar y con ese fin, ese mismo año, llevó a cabo un estudio preliminar de su oferta exportable, que incluyó la selección del producto y el acopio de información pertinente sobre los países que entonces lo importaban. Se examinó también los incentivos a la exportación que ofrecía el país y el procedimiento administrativo de exportación y se realizó un análisis de costos. Tres afios después, en 1990, la empresa tomó la decisión de empezara vender al exterior.

- Consultor y profesor del Centro Interamericano de Comercialización, CıCOM, órgano de la OEA. del gobierno brasileño y de la Fundación Getulio Vargas, Rio de Janeiro (1992).

\section{La oferta exportable}

La oferta exportable de la empresa consta de tres productos: mangos frescos, papayas y piñas (ananás) en conserva. El Cuadro $I$ presenta los volúmenes que se piensa colocar en los mercados externos.

\begin{tabular}{|lcc|}
\hline \multicolumn{3}{c}{ Cuadro 1 } \\
\hline Producto & $\begin{array}{c}\text { Oferta } \\
\text { Exportable } \\
\text { (anual) }\end{array}$ & $\begin{array}{c}\text { Porcentaje de } \\
\text { su Produccion }\end{array}$ \\
\hline $\begin{array}{l}\text { Mangos (Haden) } \\
\text { Papayas }\end{array}$ & $\begin{array}{c}100 \mathrm{tm} \\
85 \mathrm{tm}\end{array}$ & $\begin{array}{l}50 \% \\
\text { Piflas cn conserva } \\
60 \mathrm{tm}\end{array}$ \\
\hline
\end{tabular}

Harman \& Cía. S.A., que también produce los frutos y mantiene un sistema propio de comercialización interna, creó en 1988 un Departamento de Exportaciones encargado de dos tareas especificas: investigar y desarrollar mercados para los tres productos mencionados y efectuar $\mathrm{cl}$ 
trámite administrativo necesario para hacer viables los contratos de exportación. A su jefatura fue promovido uno de los vendedores más antiguos y de mayor confianza de la empresa.

Con relación a su primera tarea, el gerente de exportaciones presentó al directorio un detallado estudio sobre la oferta exportable, del cual transcribimos to siguiente:

Mangos.- El mercado internacional ha registrado un crecimiento notable -130 por ciento-en los últimos cuatro años. Los mayores importadores son Reino Unido, Francia y los Países Bajos. En la actualidad ningún país domina el mercado curopeo debido al corto periodo de producción de mangos de alta calidad, como los que produce Harman \& Cía. S.A. Los principales provecdores son Brasil, Burkina Faso, Costa de Marfil, India, Kenia, Mali, México, Pakistán, Perú, Africa del Sur, Estados Unidos, Venezuela y diversos países del Caribe.

Debido a la naturaleza del producto, los mangos deben ser transportados por avión.

Papayas.- El mercado de este producto también está en constante crecimiento. En 1989 sólo Europa Occidental compró 3.000 toneladas métricas, triplicando los volúmenes de 1985. Brasil es el principal exportador, le corresponde el 70 por ciento del mercado.

Piñas en conserva.- El principal comprador de este producto es el Mercado Comuin Europeo, que anualmente adquicre 180.000 toneladas métricas. Aun cuando las importaciones son de piñas frescas de las variedades Smooth Cayenne, Queen,
Red Spanish y Abacaxis, se ha considerado la penetración de conservas debido a la dificultad para recolectar el producto en los volúmenes requeridos. La presentación del fruto en conservas dará al producto mayor durabilidad, permitirásu mejor almacenamiento y harí posible cumplir con los compromisos de exportación adquiridos. La cmpresa podrá utilizar la capacidad instalada de su planta, que abastece el mercado nacional y el de algunos países vecinos.

El gerente de exportaciones ya ha presentado las cotizaciones de la empresa a los importadores con quienes ha hecho contacto. Ha determinado que tanto los mangos como las papayas se vendan en la posición FOB -Incotcrms 1990-puerto de embarque; y la piña en conserva, por ser de más fácil manipuleo, en la posición CFR. Incoterms 1980. También ya está decidido el mercado de destino: Reino Unido para los mangos, Francia para las papayas y Bulgaria para las piñas en conserva.

\section{Toma de decisiones}

Estando ad portas el primer embarque, el director-gerente de la empresa convocó a una reunión a los funcionarios vinculados al área de exportación. A ella asistieron, además del convocante, el gerente de exportaciones, el gerente de producción y dos asesores en comercio internacional.

Después de una exposición preliminar, la reunión derivó hacia el tema principal: determinar un sistema de envase y embalaje para los productos que se iban a exportar.

Gerente de exportaciones.- Hemos conseguido, no sin poco esfuerzo, colocar nuestros productos en el mercado ex- 
terno. Creo que los buenos precios conseguidos nos permitirán incrementar nuestras ventas. El sistema de embalaje es muy sencillo y contamos con la experiencia en la comercialización interna; nuestra empresa absorbe el 30 por ciento del mercado nacional desde 1983.

Asesor 1.- No creo que sea tan simple, pues se trata de productos altamente perecibles, a excepción de las conservas -cuya duración es mayor-, que deben llegar a su destino en óptimo estado de conservación.

Gerente de exportaciones.- Bueno, también hemos avanzado en eso. Fíjense en estas especificaciones (la información que les muestra está consignada en el Cuadro 2). minoristas los venden por unidad y muestran marcada preferencia por los frutos uniformes.

Con relación a las medidas del embalaje, son compatibles con las nuestras porque desde $1975 \mathrm{cl}$ Reino Unido está adoptando $\mathrm{cl}$ sistema métrico decimal. Algo más importante, la OCDE, de la cual forman parte el Reino Unido y Francia, logró de la CEE la aprobación de la Resolución No 203: "Normalización de embalajes de madera para frutas y verduras utilizados en el transporte y en el comercio internacional". Esta resolución precisa las dimensiones de fondo de los embalajes de madera usados por países del tercer mundo; además la OCDE ha claborado un "Plan para la aplicación de normas internacionales a las frutas y a las verduras".

\section{Cuadro 2}

Mangos: Serín enbalados en cajas de madera con capacidad para 10 a $12 \mathrm{~kg}$, suficientemente ventiladas.

Papayas: Serán embaladas en unidades que contengan maximo 8 a 10 piezas para permitir su rápido costeo.

Conservas de piña: Irain en cajas de canón con capacidad para 24 latas.

Por lo que a nosotros respecta, creo conveniente buscar la normalización de los envases y de los embalajes para proteger la calidad de nuestros productos. A mi juicio cs necesario: protegerel producto en todas las fases de la distribución, contribuir a la racionalización de las

Asesor 2.- Permítanme mostrarles una relación de los principales requisitos que deben tenerse en cuenta para el envase y el embalaje de nuestros productos (ver Cuadro 3).

Asesor 1.- Debemos tener en cuenta otros detalles. La CEE exige para los mangos, además de buen sabor, el que cstén libres de sabores extraños. Además deben estar calibrados con exactitud por tamaños, pues los comerciantes operaciones de manipulación y de transporte, facilitar la presentación adecuada de los frutos y buscar la opción más económica para la empresa. En consecuencia, el embalaje del mango y de la papaya debe cumplir dos objetivos: reducir el número de tamaños -habida cuenta de los requisitos de la paletización y las necesidades de adoptar dimensiones uniformes-y proteger y presentar satisfactoriamente el producto -robustez, estabilidad para el apilado, ventilación- 


\section{Cuadro 3}

Mangos.

- Deben ser de un tamafio uniforme.

- El peso por unidad debe oscilar entre los 225 y los 400 gramos.

- Deben ser embalados en cajas de tablero de fibra de un peso ne. to de 566 kilos.

- El envase debe contener, además, viruta de madera.

- Cada fruta debe estar envuelta en papel de seda.

- Cada caja debe contener entre 10 y 12 unidades.

Papayas

- Deben ser envasadas en eajas de cartón.

- Cada caja debe contener de 8 a 11 piezas.

- No se necesita someter las frutas a reglamento fitosanitario alguno, pues cuandoel producto llega a Francia, el Service de la Protection des Vegetaux comprobará que no tiene parásitos nocivos para la agricultura francesa.

Deben ser transportadas por avión.

Piñas en conserva

- Las latas deben ser del modelo "three piece can".

- Cada lata debe estar etiquetada e indicar nombre y dirección de la fábrica y el origen del producto.

- Las latas deben haber sido esterilizadas con las caracteristicas "open top".

Gerente de producción.- Creo que debemos distinguir muy claramente los requisitos para el envase de los correspondientes al embalaje. Durante mi último viaje a Europa pude observar cómo en numerosos países se está usando el "preembalaje", esto es, un embalaje que permite presentar el producto fresco en unidades listas para su venta directa al público. En Alemania Federal, por ejemplo, hay alrededor de cien mil tiendas que venden así. En el mercado búlgaro esto cs más simple. no sólo por el tipo de envase sino por los menores requisitos.

Asesor 2.- Justamente eso es lo que estoy sugiriendo.
Director-gerente.- Bueno, creo que es válida la observación de nuestro gerente de producción. Estimo que están claras las recomendaciones sobre el envase de cada uno de nuestros productos. Restaría ahora indicar los requisitos de embalaje.

\section{Gerente de exportaciones.- He} estudiado con detalle la "Norma general internacional recomendada para el etiquetado de los alimentos preenvasados", elaborada por el Programa Conjunto FAO/ OMS, Comisión del Codex Alimentarius. Estimo conveniente que todos la conozcamos (reparte copias fotostáticas, ver Anexo).

Asesor 1.- Cor relación al cmbalaje debemos distinguir dos tipos: el embalaje de consumo y el embalaje de transporte. Como ha señalado nuestro gerente de producción, debemos orientar nuestros mangos y papayas hacia el embalaje de consumo, dado el pequeño volumen de nuestras exportaciones. De este modo, y considerando que nuestras latas de conserva comparten esa orientación, estaremos estandarizando dentro de la compañía el tema del embalaje para no tener varias líneas para productos similares.

Creo que debemos usar madera o cartón, depende de cual sea menos costo- 
Cuadro 4

\begin{tabular}{|c|cc|}
\hline Tipos & $\begin{array}{l}\text { Coeficiente de utilización de la super- } \\
\text { ficie en los dos tipes de palctas norma- } \\
\text { lizadas (se considera adecuado un coe- } \\
\text { ficiente minimo del 90\%) }\end{array}$ \\
& Paleta & Paleta \\
& $80 \mathrm{~cm} \times 120 \mathrm{~cm}$ & $100 \mathrm{~cm} \times 120 \mathrm{~cm}$ \\
(centrimetros) & (Porcentaje) & (Porcentaje) \\
$60 \times 40$ & 100,00 & 100,00 \\
$50 \times 30$ & 93,75 & 100,00 \\
$40 \times 30$ & 100,00 & 100,00 \\
$50 \times 40$ & 83,40 & 100,00 \\
$56 \times 35$ & 81,66 & 81,66 \\
\hline
\end{tabular}

so o del requisito exigido por el comprador. En el cuadro que pueden ver en la pizarra (ver Cuadro 4 ) he calculado las medidas posibles de estos embalajes, sean para mangos o para papayas. En el caso de las piñas en conserva para Bulgaria, propongo "tambores" de 100 a 150 litros para su reenvase en el mercado de destino.

Gerente de exportación.- Yo no sé si el último planteamiento de nuestro asesor es compatible con las condiciones contractuales de venta. En cuanto al preembalaje, creo que puede originar algunos problemas; de hecho algunos aspectos técnicos todavía están en estudio, como la respiración del producto embalado en contenedores de plástico rígidos o flexibles.

Los problemas técnicos consisten principalmente en determinar la unidad de venta, tanto con relación al peso máximo como al material utilizado; $\mathrm{el}$ sistema de distribución; y el tipo de contenedor para transporte y manipulación que ha de utilizarse con los preembalajes normalizados, según los define la OCDE. Debe determinarse también las fases en que ha de efectuar- se el preembalaje, es decir, fases de producción, elaboración, embalaje o venta al por menor.

Desde el punto de vista económico, la preferencia de los minoristas por el producto preembalado en comparación con las formas tradicionales de presentación depende de los siguientes factores: inversión en equipo de preembalaje $\mathrm{y}$ amortización de las inversiones, y del costo del preembalaje.

Asesor 1.- Pero como nosotros hemos planteado el embalaje en cartón o madera, creo que no se darían los problemas mencionados por nuestrogerente de exportaciones.

Asesor 2.- Quisiera añadir algunas indicaciones respecto del etiquetado de las latas de conserva. Debe consignarse: nombre y dirección de la empresa, descripción clara de las conservas, peso y volumen neto, periodo de validez de las conservas, condiciones en que deberá almacenarse el producto después de haber sido abierto el envase, instrucciones de uso.

Gerente de producción.- Es conveniente hablar con la compañía transportado$\mathrm{ra}$, pues obedece reglamentos $\mathbf{e}$ instrucciones con relación a los contenedores que se pueden usar en el transporte, y conoce las "marcas precautorias" para la manipulación en el avión. Respecto de esto existen las normas internacionales de la ISO "Marcas gráficas para la manipulación de mercancías-símbolos generales", conocidas con el Código ISO/R.780. 1968. 
Director-gerente.- Bueno, creo que con todo lo dicho hoy, nuestro gerente de exportaciones tiene material suficiente para planificar un sistema de normalización de envases y de embalajes para ésta y las siguientes operaciones internacionales de la compañía.

\section{El plan empresarial de normalización}

El gerente de exportaciones se dedicó entonces a diseñar un plan inicial. El esquema de trabajo comprendía las siguientes áreas:

- La Dirección-Gerencia

- Finanzas

- Gerencia de Exportaciones

- Gerencia de Producción

- Diseño

- Asesoría Jurídica

El plan se dividió en dos partes:

a) La primera buscaría resolver el problema del envase y del embalaje de los tres primeros productos de exportación. En consecuencia se habría de determinar:

- Tipos de envase

- Dimensiones

- Peso del producto para cada envase

- Tipo de embalaje

- Dimensiones del embalaje

- Marcas y símbolos

- Etiquetado (forma y descripciones)

- Peso del embalaje

Para esto se habría de tener en consideración:

- Clasificación por peso de los embalajes (peso bruto, neto, tara y peso legal)

- Material a ser utilizado
- Costo de los envases y embalajes.

- Medio de adquirirlos (provecdores o fábricas)

b) La segunda etapa consistiría en diseñar -y repartir entre las diferentes áreas de la empresa- el conjunto de responsabilidades que debería asumirse para establecer un sistema de normalización de envases y de embalajes. Tal esquema involucraría lo siguiente:

Finanzas (Departamento de Compras)

- Obtención de suministros de envases o embalajes adecuados, materiales y equipo de envase y embalaje conforme a las necesidades de la empresa.

- Cálculo de los costes de envase o embalaje, según sean adquiridos de terceros o producidos por la empresa.

- Evaluación y pedido de materiales.

-Presupuestos anuales de envase y embalaje.

\section{Gerencia de Producción}

- Aspectos técnicos del envase.

- Preparación de las especificaciones.

- Prospección de materiales y métodos.

- Creación del envase en la empresa.

- Aprobación de nuevos abastecedores $y$ materiales.

- Establecimiento del control, normas y procedimientos de calidad.

\section{Diseño}

- Logotipos, normas sobre el color, etc.

- Forma del envase y decoración de la superficie y/o subcontratos con diseñadores del exterior.

- Preparación de instrucciones para el diseño.

- Preparación artística y aprobación de las pruebas de impresión de los abastecedores. 


\section{NOTA PEDAGOGICA}

Este caso está dirigido a operadores de comercio exterior, gerentes de producción y alumnos de Administración y Mercadotecnia; su finalidades ayudarlos a poner en práctica sus conocimientos sobre embalaje, control de calidad y comercialización internacional de productos tropicales, permiténdoles conocer, además, los elementos básicos de estandarización internacional.

El caso está tomado de la vida real y puede ser aplicado a cualquier país latinoamericano. Pone en evidencia la importancia de los sistemas de control de calidad y de estandarización internacional para disminuir costos. Adicionalmente, aun cuando no es su objetivo principal, mucstra las exigencias de los países desarrollados que se presentan bajo las formas de "barreras técnicas".

\section{Objetivos}

- Analizar los diferentes aspectos que el tema del envase y el embalaje de frutas tropicales suscita cuando una empresa latinoamericana tipocxporta hacia los países curopeos o hacia el mereado de Estados Unidos de América.

- Exponer los principios básicos de un sistema de control de calidad en una empresa agroindustrial.

- Desarrollar técnicas de toma de decisiones en el campo del comercio exterior. así como en la formación de la gerencia de exportaciones de una empresa mediana.

\section{Guía para la discusión}

1. Actúe como si fuera asesor del gerente de exportaciones o como si fuera él mismo.

2. Diseñe el esquema de envase y de embalaje para los tres productos. Siga los pasos recomendados en el plan diseñado por el gerente de exportaciones. ¿QuÉ otros asuntos incluiría usted?

3. Especifique cada una de las acciones a desarrollar para llevar a la práctica la segunda etapa del plan propuesto por el gerente de exportaciones.

¿Qué aspectos técnicos, detalles, politicas añadiría usted para desarrollar el plan?

¿Qué rubros consideraría para establecer los costos?

¿Qué opina sobre la opción de exportar las conservas en toneles en lugar de en latas?

4. Elabore un conjunto detallado de acciones para la primera etapa del plan del gerente de exportaciones.

5. ¿Es conveniente un sistema de normalización? 


\section{Anexo \\ PRINCIPALES ASPECTOS DE LA NORMA GENERAL INTERNACIONAL RECOMENDADA PARA EL ETIQUETADO DE LOS ALIMENTOS PREENVASADOS (CAC/RS 1 -1969)}

\section{Definición de los términos}

Para los fines de esta norma se entenderá por:

Etiqueta: toda etiqueta, marca, imagen (u otro material) descriptiva o gráfica, escrita, im. presa, estarcida, marcada, grabada en relieve o en huecograbado o adherida al envase de un alimento.

Etiquetado: la etiqueta propiamente dicha y cualquier material escrito, impreso o gráfico relativo a un alimento y que acompañe a éste.

Envase: todo recipiente utilizado para envasar completa o parcialmente todo alimento destinado a la venta, comprendiendo los materiales empleados para envolverlo.

Preenvasado: todo alimento preempaquetado o preparado previamente, listo para la venta al por menor en un recipiente o envase.

Ingrediente: toda sustancia, incluyendo los aditivos alimentarios, empleada en la fabricación o preparación de un alimento, que se encuentra en el producto final.

Componente: cualquier sustancia que forme parte de un "ingrediente".

\section{Principios generales}

2.1 Los alimentos preenvasados no deberán describirse ni presentarse con una etiqueta o etiquetado en una forma que sea falsa, equívoca o engañosa, o susceptible de crear en algún modo una impresión errónea respecto de su naturaleza en algún aspecto.

2.2 Los alimentos preenvasados no debe- rán describirse ni presentarse con una etiqueta o etiquetado en los que se empleen palabras, ilustraciones $\mathrm{u}$ otras representaciones gráficas que se refieran, o sugieran, directa o indirectamente a cualquier otro producto con el que el alimento pueda confundirse, ni en una forma tal que pueda inducir al comprador o al consumidor a suponer que el alimento se relaciona en forma alguna con aquel otro producto.

\section{Etiquetado obligatorio de los alimentos preenvasados}

Las etiquetas de todos los alimentos preenvasados deberán llevar la información exigida por los párrafos 1 a 5 de esta sección y que sea aplicable al etiquetado del alimento de que se trate, excepto cuando expresamente se indique otra cosa en una norma específica del Codex.

\subsection{Nombre del alimento}

a) El nombre deberá indicar la verdadera naturaleza del alimento y, normalmente, deberá ser específico y no genérico.

b) Cuando se hayan establecido uno o varios nombres para un alimento en una normadel Codex, deherá utilizarse, por lo menos, uno de estos nombres.

c) En otros casos deberá utilizarse el nombre común usual, si existe alguno.

d) Cuando no exista un nombre común usual deberá emplearse un nombre descriptivo apropiado.

e) No obstante, podrá emplearse un nombre "acunado" o de "fantasía" siempre que no sea 
equívoco y vaya acompañado de un término adecuadamente descriptivo.

\subsection{Lista de ingredientes}

a) En la etiqueta deberá indicarse la lista completa de los ingredientes por orden decreciente de proporciones, excepto:

i) Cuando se prescriba otra cosa en una norma del Codex.

ii) Cuando se trate de alimentos deshidratados, destinados a ser reconstituidos mediante la adición de agua. En este caso los ingredientes podrán enumerarse por orden decreciente de proporciones en el alimento reconstituido siempre que la lista de los ingredientes se encabece con una indicación. como por cjemplo. "ingredientes después de reconstituidos".

iii) Cuando se trate de alimentos para los que la legislación nacional no exija una declaración completa de ingredientes, siempre que tales exeneiones se hayan otorgado porque el alimento es de una composición bien conocida, la omisión de los ingredientes no sea perjudicial para el consumidor y la información que figura en la etiqueta permita al consumidor comprender su naturaleza.

b) Cuando un ingrediente de un alimento tenga más de un componente, los nombres de los componentes deberín incluirse en la lista de los ingredientes, excepto cuando el ingrediente sea un alimento para el cual se haya establecido una norma del Codex y dicha norma no exija la lista completa de ingredientes.

c) En la lista de ingredientes deberá emplearse un nombre expecifico para los ingredientes, excepto:

i) Cuando se trate de ingredientes que pertenezcan a las respectivas clases. En este caso podrán usarse los siguientes títulos genéricos:
grasas animales
aceites animales
grasas vegetales
aceite vegetales
hierbas
especias
almidones (excepto almidones modi-
ficados)

ii) Cuando se trate de sustancias que pertenezcan a estas respectivas clases y fi. guren en las normas del Codex o en las listas de aditivos alimentarios del Codex, y su uso en los alimentos haya sido autorizado de un modo general. En este caso podrán emplearse los siguientes títulos genéricos:

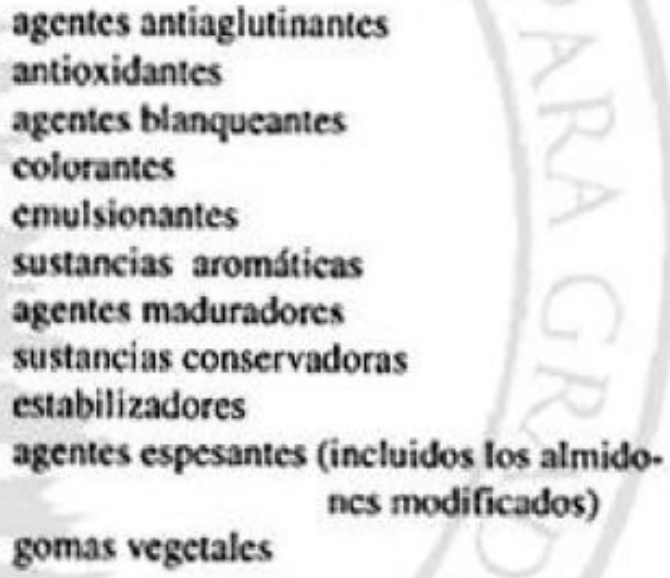

d) In la lista de ingredientes đeberá indi. carse el agua añadida si esta indicación ha de tener como resultado una mejor comprensión por parte del consumidor đe la composición del producto, excepto cuando el agua forme parte de ingredientes, tales como la salmuera, el ja. rabe o el caldo empleados en un alimento compuesto.

\subsection{Contenido neto}

a) El contenido neto deberá indicarse en el sistema métroo (unidades del "Sistema Inter. nacional"), en el sistema "Avoirdupois" o en ambos sistemas de medidas, de acuerdo con las necesidades del país en que se venda el alimento. Esta đeclaración deberá hacerse de la siouiente formo. 
i) En volumen para los alimentos líquidos.

ii) En peso para los alimentos sólidos, excepto cuando tales alimentos se vendan usualmente por unidades; $\mathrm{en}$ tal caso podrá indicarse el número.

iii) En peso o volumen para los alimentos semisólidos o viscosos.

b) En los alimentos envasados con un medio liquido que normalmente se desecha antes de consumirlos, deberá indicarse el peso escurrido del alimento.

\subsection{Nombre y dirección}

a) Deberá indicarse nombre y dirección de: fabricante, envasador, distribuidor, importador. exportador o vendedor del alimento.

\subsection{País de origen}

a) Deberá indicarse el país de origen del alimento cuando su omisión pueda resultar engañosa o equívoca para el consumidor.

b) Cuando un alimento se someta en un segundo país a una elaboración que cambie su naturaleza, el país en el que se efectúe la elaboración deberá considerarse como país de origen para los fines de etiquetado. 